INRA Prod. Anim.,

2013, 26 (4), 303-316

\title{
Des aliments à base de végétaux pour les poissons d'élevage
}

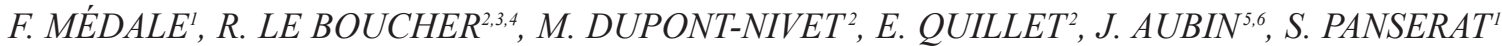 \\ ${ }^{1}$ INRA, UR1067 NuMeA, F-64310 St Pée-sur-Nivelle, France \\ 2 INRA, UMR1313 GABI, F-78350 Jouy-en-Josas, France \\ ${ }^{3}$ Ifremer, UMR110 Intrepid, F-34250 Palavas-les-Flots, France \\ 4 AgroParisTech, UMR1313 GABI, F-75231 Paris 05, France \\ ${ }^{5}$ INRA, UMR 1069 SAS, F-35042 Rennes cedex, France \\ ${ }^{6}$ AgroCampus Ouest, UMR 1069 SAS, F-35042 Rennes cedex, France
}

Courriel : françoise.medale@st-pee.inra.fr

La croissance de l'aquaculture mondiale et la nécessaire préservation des ressources naturelles marines imposent de faire évoluer la composition des aliments pour les poissons d'élevage. Découvrez les conséquences des formules d'aliments contenant de plus en plus de végétaux et les verrous à lever pour diminuer encore l'incorporation de ressources marines dans les aliments aquacoles.

Depuis 30 ans, la consommation mondiale de poissons et de crustacés s'est accrue, passant de 50 Millions de tonnes (Mt) en 1980 à $131 \mathrm{Mt}$ en 2011 (FAO 2012). Cette augmentation est due à la fois à la croissance de la population mondiale et à la hausse de la consommation par habitant. L'offre mondiale de poisson pour l'alimentation humaine, de $11,3 \mathrm{~kg} /$ personne en 1980 , a atteint le niveau record de $18,8 \mathrm{~kg} /$ personne en 2011 (FAO 2012). Les captures de pêche sont restées stables depuis 30 ans autour de $90 \mathrm{Mt}$ dont 60 à $67 \mathrm{Mt}$ utilisées pour l'alimentation humaine (figure 1). La hausse de la demande a donc été couverte par les produits d'élevage dont la production mondiale a connu un essor spectaculaire, passant de moins de $4 \mathrm{Mt}$ en 1980 à 63 Mt en 2011 (figure 1), soit autant que les captures de pêche pour la consommation humaine.

L'élevage intensif de poissons ne s'est développé qu'à partir des années 1960 avec l'apport de nourriture sous forme d'aliments composés. Les farines et huiles de poisson ont été utilisées comme ingrédients majoritaires des aliments aquacoles, notamment pour les espèces de haut niveau trophique comme les salmonidés (truites, saumons) et les poissons marins. Ces matières premières contiennent tous les nutriments pour couvrir les besoins nutritionnels de ces espèces et l'huile de poisson enrichit leur chair en acides gras polyinsaturés à longue chaîne n-3 (AGPI-LC n-3), bénéfiques pour la santé humaine.
L'essor continu de l'aquaculture $(+8,8 \%$ en volume de production par an entre 1980 et 2010) a accru la demande en aliments et donc en matières premières qui les composent. Or, limitées par la disponibilité de la ressource, les captures de la pêche minotière (petits pélagiques non destinés à la consommation humaine) ont été maintenues autour de $25 \mathrm{Mt} / \mathrm{an}$ au cours des 30 dernières années (figure 1) fournissant 5 à $6 \mathrm{Mt}$ de farine de poisson et 1 à 1,4 Mt d'huile de poisson. Afin de faire face à la demande, il a fallu recourir à des matières premières alternatives. Après l'interdiction de l'utilisation de produits d'animaux terrestres dans l'alimentation des poissons d'élevage en Europe, le prix des matières premières d'origine halieutique et la prise de conscience que le développement de l'aquaculture ne pouvait se faire au détriment des ressources naturelles marines ont fortement stimulé l'évolution des régimes vers davantage d'ingrédients végétaux (Naylor et al 2009).

Cet article est consacré aux aliments des salmonidés et poissons marins, qui sont, avec les crevettes, les espèces les plus consommatrices de farine et d'huile de poisson (figure 2). L'évolution de la composition de leur régime alimentaire

Figure 1. Evolution, entre 1980 et 2011, des captures de pêche pour l'alimentation humaine et animale et des produits de l'aquaculture (hors plantes et mollusques) en millions de tonnes.

Source : FAO 2012.

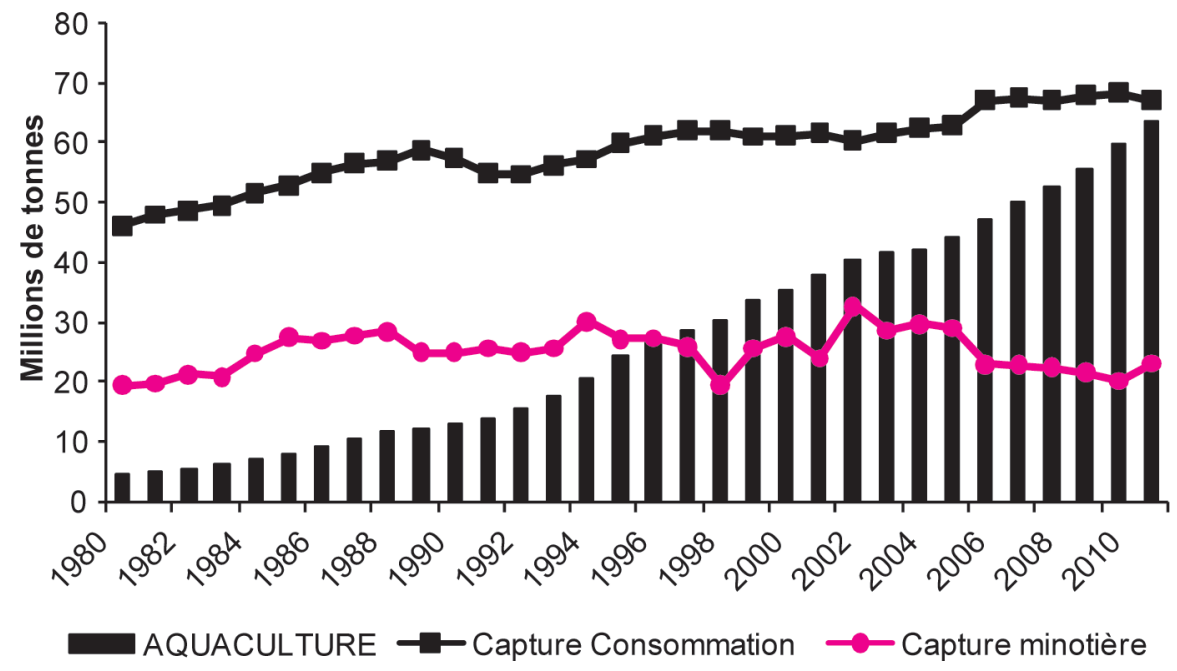


Figure 2. Répartition de l'usage des farines et huiles de poisson pour l'alimentation des différentes espèces d'élevage aquacole, en 2008. Source : FAO 2012.

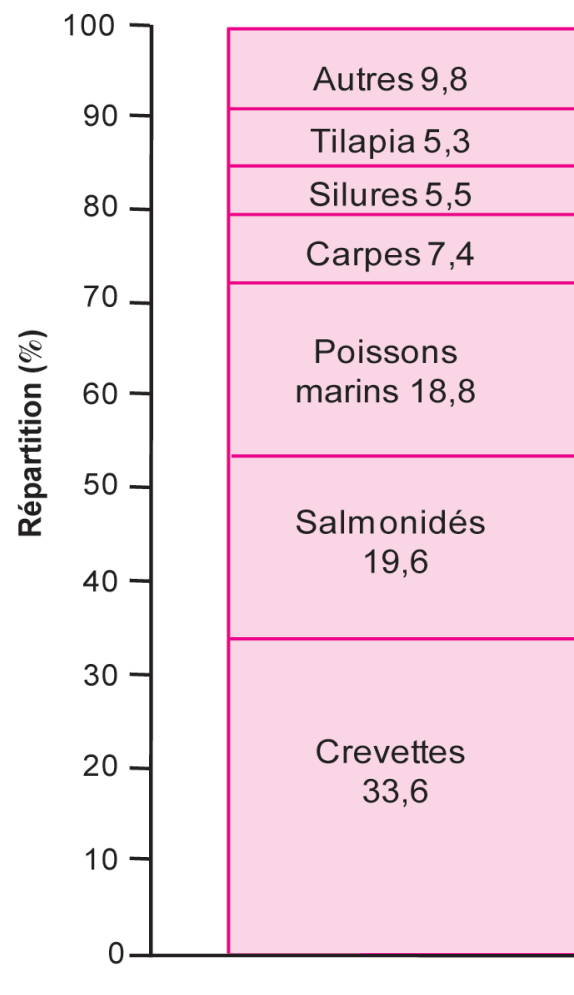

Farines de poisson

est donc particulièrement cruciale pour la durabilité de leur élevage. Dans la pratique, la farine et l'huile de poisson sont remplacées simultanément, mais nous traiterons la substitution de chacune séparément afin de mettre en évidence les enjeux et les conséquences spécifiques.

\section{1 / Les contraintes liées aux besoins nutritionnels des poissons de haut niveau trophique}

Les poissons de haut niveau trophique catabolisent préférentiellement les protéines et les lipides pour couvrir leurs besoins énergétiques en raison de capacités limitées à utiliser efficacement l'énergie des glucides alimentaires (Médale et Guillaume 1999). Leur ration doit donc être riche en protéines et en lipides. En effet, l'adjonction de lipides, qui sont très bien digérés (à plus de 90\%), permet de limiter l'utilisation des protéines pour la production d'énergie chez la plupart de ces espèces. Les déchets azotés issus du catabolisme des acides aminés sont alors diminués et la rétention protéique accrue (Médale et Guillaume 1999).

Pour une efficacité optimale des performances de production, les protéines doivent représenter 38 à $42 \%$ de la Matière Sèche (MS) de la ration pour les salmo-

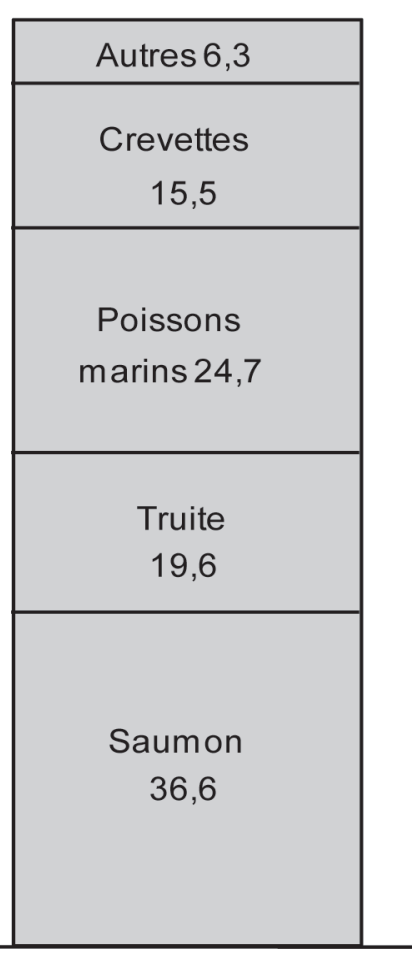

Huiles de poisson

nidés et 45 à $55 \%$ pour les poissons marins contre $30 \%$ pour des poissons de plus faible niveau trophique comme la carpe ou le tilapia qui sont plus efficaces pour produire de l'énergie à partir des glucides alimentaires (NRC 2011). Les sources protéiques doivent apporter les 10 Acides Aminés Indispensables (AAI) aux poissons, qui sont les mêmes que pour les autres animaux. Les besoins quantitatifs sont du même ordre de grandeur et la rétention azotée est optimale lorsque l'apport est réparti à parts égales entre AAI et Acides Aminés Non Indispensables (AANI) (46/54, Green et al 2002). Les taux de lipides alimentaires se situent généralement entre 28 et $35 \%$ pour les salmonidés et entre 20 et $25 \%$ pour les poissons marins à l'exception des poissons plats comme la sole (NRC 2011, Borges et al 2012). Dans ces conditions, les protéines sont retenues dans le muscle avec une très grande efficacité : 50 à $70 \%$ contre 25 à $40 \%$ chez les mammifères (Mambrini et Guillaume 1999). Leur caractère poïkilotherme permet aux animaux aquatiques de faire l'économie des dépenses d'énergie pour la thermorégulation. La rétention protéique élevée, corollaire des faibles besoins énergétiques, fait des poissons, en particulier les poissons d'eaux froides comme les salmonidés, des convertisseurs très efficaces des aliments.

Outre l'énergie digestible, les sources lipidiques de l'aliment doivent fournir les acides gras essentiels. Les poissons ont besoin d'AGPI de la série n-3 ou $\omega 3$. Les salmonidés ont la capacité de synthétiser les 2 AGPI-LC bioactifs, l'acide eicosapentaénoïque (EPA, C20:5 n-3) et l'acide docosahexaénoïque (DHA, C22:6 n-3) à partir du précurseur, l'acide $\alpha$-linolénique (ALA, C18:3 n-3). Cependant, l'apport direct d'EPA et de DHA est plus efficace. Par contre, les poissons marins ont des capacités très faibles voire inexistantes de synthèse d'EPA et DHA à partir du précurseur, ces acides gras doivent donc impérativement leur être apportés par l'alimentation (NRC 2011).

\section{2 / Remplacement de la farine de poisson par des produits végétaux}

Le principe de la substitution est basé sur le fait que la farine de poisson n'est pas une matière première indispensable, ce sont les nutriments qu'elle apporte qui le sont. Cependant, sa composition complexe la rend difficile à remplacer. Riche en protéines (65 à $72 \%$ - tableau 1) hautement digestibles et équilibrées en AAI et AANI, elle contient aussi des lipides (5 à 12\%) qui ne sont pas totalement éliminés lors de sa fabrication et des minéraux provenant du squelette et des écailles (Hertrampf et Pieded-Pascual 2000).

\section{1 / Les sources protéiques végé- tales : composition et stratégies d'utilisation}

Sur la base de leur composition et de leur disponibilité sur le marché, les produits végétaux les plus utilisés sont issus d'oléagineux (soja, colza, tournesol), de céréales (maïs, blé) et de protéagineux (lupins, pois). La démarche a consisté à les tester individuellement en les incorporant à différentes doses dans les aliments pour les poissons en phase de grossissement en remplacement de la farine de poisson. Nous résumons cidessous leurs atouts et limites ainsi que les stratégies mises en œuvre pour optimiser leur utilisation en alimentation aquacole.

\section{a) Le taux protéique et le profil en acides} aminés

Le taux protéique des matières premières végétales est faible en comparaison de celui de la farine de poisson : $26 \%$ pour le pois, $41 \%$ pour le tourteau de colza, 48 à $55 \%$ pour le tourteau de soja contre 65 à $72 \%$ dans les farines de poisson (tableau 1). Afin de satisfaire les besoins en protéines des poissons, on a recours à des concentrés protéiques tels que les glutens de blé et de maïs ou les concentrés de soja et de colza mais 
Tableau 1. Caractéristiques (en \% de la matière sèche) de la farine de poisson et des produits végétaux les plus utilisés comme sources protéiques dans les aliments aquacoles en Europe.

Sources : NRC 2011 ; Feedipedia 2013 : http://www.feedipedia.org/

\begin{tabular}{|l|c|c|c|c|c|}
\hline Ingrédients & Origine & Protéines & Lipides & Amidon & Fibres \\
\hline Farine d'anchois & Amérique Sud & 71 & 8,2 & $/$ & $/$ \\
\hline $\begin{array}{l}\text { Blé } \\
\text { Entier } \\
\text { Gluten }\end{array}$ & Europe & $\begin{array}{c}11-15 \\
81-90\end{array}$ & $\begin{array}{c}1,8-2,0 \\
1,7\end{array}$ & $\begin{array}{c}65 \\
/\end{array}$ & $\begin{array}{c}13,8 \\
/\end{array}$ \\
\hline Maïs Gluten & Europe & $63-70$ & 2,4 & $/$ & $/$ \\
\hline $\begin{array}{l}\text { Soja } \\
\text { Tourteau } \\
\text { Concentré protéique }\end{array}$ & USA, Brésil & $46-54$ & 0,9 & 2,7 & 23,3 \\
\hline Colza Tourteau & Europe & 41 & 4 & 1,5 & 22,5 \\
\hline Pois dépelliculé extrudé & Europe, Canada & 28 & 1,6 & 45,4 & 7,7 \\
\hline Lupin blanc doux & Bassin méditerranéen, Australie & 33 & 7,3 & 1,4 & 41,5 \\
\hline
\end{tabular}

ces produits sont onéreux, c'est pourquoi ils ne constituent qu'une partie de l'apport protéique de la ration.

La composition en acides aminés des végétaux est différente de celle des farines de poisson (tableau 2). La grande majorité des sources protéiques végétales ont des teneurs limitées en lysine, à l'exception du gluten de blé, et en méthionine, à l'exception du gluten de maïs. Quand l'apport alimentaire en acides aminés n'est pas précisément adapté aux besoins de l'animal, le catabolisme azoté augmente, la rétention protéique est réduite et les rejets azotés accrus (Médale et Kaushik 2009). Pour éviter les carences, les sources végétales sont mélangées et si nécessaire, des acides aminés de synthèse sont ajoutés sous forme cristalline (Rodehutscord et al 1997).

\section{b) Les glucides}

Les produits issus des végétaux terrestres contiennent des taux élevés de glucides (tableau 1). Certains, comme les farines de céréales et le pois sont riches en amidon, d'autres, comme les tourteaux de soja, de colza et le lupin sont riches en glucides membranaires complexes (pectines, hémicellulose, pentosanes, cellulose, lignine regroupés dans le tableau 1 sous le terme générique de fibres). Les concentrés protéiques en sont exempts mais leur coût limite leur utilisation.

L'amidon cru est faiblement digéré par les poissons de haut niveau trophique en raison d'une activité limitée de l'amylase. Son coefficient d'utilisation digestive (quantité digérée par rapport à l'ingéré) est de 30 à $40 \%$, selon le taux d'amidon du régime, la température et l'espèce (NRC 2011). Des traitements hydrothermiques

Tableau 2. Teneurs en acides aminés indispensables (\% de la matière sèche) de la farine d'anchois et de sources protéiques végétales.

Source : NRC 2011.

\begin{tabular}{|c|c|c|c|c|c|c|c|}
\hline \multirow{2}{*}{$\begin{array}{l}\text { Acides aminés } \\
\text { indispensables }\end{array}$} & \multicolumn{7}{|c|}{ Matières premières } \\
\hline & $\begin{array}{c}\text { Farine } \\
\text { d'Anchois }\end{array}$ & $\begin{array}{l}\text { Tourteau } \\
\text { de Soja }\end{array}$ & $\begin{array}{l}\text { Tourteau } \\
\text { de Colza }\end{array}$ & $\begin{array}{l}\text { Farine } \\
\text { de Lupin }\end{array}$ & $\begin{array}{c}\text { Pois } \\
\text { dépelliculé }\end{array}$ & $\begin{array}{l}\text { Gluten } \\
\text { de Blé }\end{array}$ & $\begin{array}{l}\text { Gluten de } \\
\text { Maïs }\end{array}$ \\
\hline Arg & 4,0 & 4,0 & 2,5 & 3,6 & 2,1 & 4,3 & 2,1 \\
\hline His & 1,7 & 1,4 & 1,2 & 0,8 & 0,6 & 2,3 & 1,3 \\
\hline Ileu & 3,3 & 2,9 & 1,6 & 1,5 & 0,9 & 4,2 & 2,5 \\
\hline Leu & 5,4 & 4,2 & 2,8 & 2,6 & 1,7 & 7,1 & 10,3 \\
\hline Lys & 5,5 & 2,5 & 2,2 & 1,7 & 1,6 & 5,5 & 1,2 \\
\hline Met & 2,1 & 0,8 & 0,8 & 0,3 & 0,2 & 1,8 & 2,1 \\
\hline Phe & 2,9 & 3,0 & 1,6 & 1,3 & 1,1 & 5,0 & 4,2 \\
\hline Thr & 2,3 & 2,2 & 1,6 & 1,3 & 0,9 & 1,8 & 2,2 \\
\hline Tryp & 0,8 & 0,8 & 0,5 & 0,3 & 0,2 & 1,2 & 0,3 \\
\hline Val & 3,8 & 3,0 & 2,1 & 1,4 & 1,1 & 4,5 & 3,0 \\
\hline
\end{tabular}


tels que l'extrusion sont nécessaires pour le rendre plus digestible. En outre, l'ingestion d'amidon digestible au-delà d'un seuil de $20 \%$ de la ration provoque une hyperglycémie postprandiale persistante et des perturbations métaboliques souvent associées à une baisse du taux de croissance chez les salmonidés et les poissons marins (Enes et al 2011, Panserat et al 2013). Tous les acteurs du métabolisme glucidique sont présents chez ces espèces mais leur régulation est atypique (Polakof et al 2012). Les matières premières doivent donc être choisies de façon à limiter les quantités d'amidon dans la ration en deçà du seuil de $20 \%$ de la MS.

Les fibres présentes dans certains produits végétaux utilisés comme sources protéiques ne sont pas digérées par les poissons quelles que soient les espèces. Les essais de traitement par des enzymes pour les pré-digérer se sont révélés peu efficaces et les poissons se montrent intolérants aux sucres simples tels que le xylose et le galactose qui sont libérés (Stone 2003). Les fibres insolubles peuvent réduire la digestibilité des lipides et des protéines de l'aliment, en les emprisonnant dans un réseau qui gêne l'accès des enzymes digestives à leur substrat. Elles stimulent aussi le péristaltisme du tube digestif et réduisent l'absorption intestinale des lipides. Il convient donc de limiter au maximum l'incorporation de fibres dans les aliments aquacoles.

\section{c) Les facteurs antinutritionnels}

Les végétaux contiennent des substances de diverse nature qui peuvent pertur- ber l'appétit, la digestion, l'absorption des nutriments et le métabolisme des animaux, affectant leur croissance et parfois leur santé. Les principaux facteurs antinutritionnels (ANF «antinutritional factor») présents dans les produits végétaux utilisés en alimentation aquacole et leurs effets sont résumés dans le tableau 3 . Souvent, les mécanismes responsables des effets observés ne sont pas élucidés et des interactions entre différentes substances sont soupçonnées. C'est l'hypothèse avancée pour expliquer les sévères entérites provoquées par des aliments riches en soja chez le saumon (Van den Ingh et Olli 1996, Knudsen et al 2007, Krogdahl et al 2010).

La variété des facteurs antinutritionnels dans les végétaux, la variabilité de leur contenu, leurs interactions potentielles et les différences de sensibilité entre espèces de poissons constituent un frein majeur à l'utilisation des végétaux en alimentation aquacole. Pour limiter les effets négatifs, différentes stratégies sont adoptées. Lorsque la substance indésirable pour l'alimentation animale n'est pas indispensable à la plante, des variétés à faible taux de ces substances peuvent être sélectionnées ; par exemple il existe du colza à faible teneur en glucosinolates. Lorsque les ANFs sont présents dans l'enveloppe des graines, le retrait de l'enveloppe permet d'en éliminer une partie, ainsi les concentrés protéiques contiennent moins d'ANFs que les tourteaux ou les graines entières. Les antiprotéases ou les lectines sont détruites par la chaleur lors de l'extrusion. Cependant, certains composés aux propriétés anti-nutritionnelles, comme l'acide phytique, sont nécessaires à la plante, ils ne peuvent pas être éliminés par sélection génétique et résistent aux traitements physiques. Il faut alors contrecarrer leurs effets. Par exemple, pour rendre disponible le phosphore séquestré par l'acide phytique présent dans les végétaux, l'addition de phytase qui dégrade la liaison du phosphore phytique se révèle efficace pour augmenter la biodisponibilité du phosphore (Cao et al 2007).

\section{d) Le taux de lipides et la composition en acides gras}

Les produits végétaux utilisés comme substituts à la farine de poisson ont des teneurs en lipides faibles, à l'exception du lupin (tableau 1). Parmi les lipides résiduels contenus dans la farine de poisson, on trouve des AGPI-LC n-3, des phospholipides et du cholestérol. Les produits végétaux sont dépourvus d'EPA et de DHA. Leur teneur en phospholipides est très faible ; seul le tourteau de soja non délipidé en contient des quantités appréciables. Dans les aliments aquacoles à base de végétaux, les phospholipides sont le plus souvent apportés sous forme de lécithine de soja. Le cholestérol, stérol prédominant chez les animaux incluant les poissons, représente moins de $5 \%$ des stérols totaux chez les végétaux. Au contraire les plantes contiennent des phytostérols dont les effets sur le métabolisme des poissons ne sont pas encore complètement connus et qui peuvent affecter la reproduction de certaines espèces (Nakari et Erkomaa 2003).

Tableau 3. Facteurs antinutritionnels présents dans des produits végétaux couramment utilisés en alimentation aquacole et principaux effets délétères ou fonction affectée.

Sources : Francis et al 2001, Krogdahl et al 2010, NRC 2011.

\begin{tabular}{|c|c|c|c|c|c|}
\hline \multirow[b]{2}{*}{ Facteurs antinutritionnels } & \multicolumn{4}{|c|}{ Matières premières } & \multirow[b]{2}{*}{ Effets/Fonction affectée } \\
\hline & $\begin{array}{l}\text { Tourteau } \\
\text { de Soja }\end{array}$ & $\begin{array}{l}\text { Tourteau } \\
\text { de Colza }\end{array}$ & $\begin{array}{l}\text { Farine de } \\
\text { Lupin }\end{array}$ & $\begin{array}{c}\text { Pois } \\
\text { dépelliculé }\end{array}$ & \\
\hline Acide phytique & $x$ & $x$ & & $x$ & Digestion du $\mathrm{P}$ et des protéines \\
\hline Allergènes & $x$ & & & & Immunité, entéropathies \\
\hline Alcaloïdes & & & $x$ & & Appétit \\
\hline Antivitamines & $x$ & & & $x$ & Métabolisme \\
\hline Glucosinolates & & $x$ & & & Appétit, hyperthyroïdie \\
\hline Inhibiteurs de protéinases & $x$ & $x$ & $x$ & $x$ & Digestion \\
\hline Lectines & $x$ & & & $x$ & Absorption, entéropathies \\
\hline Phytooestrogènes & $x$ & & $x$ & & Reproduction \\
\hline Saponines & $x$ & & $x$ & $x$ & Entéropathies, digestion \\
\hline Tannins & & $X$ & & $x$ & Digestion \\
\hline
\end{tabular}




\section{2 / Effets des aliments à base de sources protéiques végétales sur les poissons}

\section{a) Taux de substitution et croissance}

L'association des connaissances issues des recherches a permis de repousser les limites de la substitution de la farine de poisson chez toutes les espèces à condition d'utiliser différents produits végétaux en mélange (Collins et al 2013). Dans les aliments pour salmonidés et poissons marins, 80 à $95 \%$ de la farine de poisson peut ainsi être substituée sans effets délétères. En revanche, le remplacement total de la farine de poisson par des produits végétaux provoque, chez les espèces de haut niveau trophique, une diminution du taux de croissance et de l'efficacité alimentaire bien que les éléments nutritifs nécessaires soient présents dans l'aliment (Gómez-Requeni et al 2004, Vilhelmsson et al 2004, Panserat et al 2008, Dupont-Nivet et al 2009, Alami-Durante et al 2010, LeBoucher et al 2012 et 2013).

\section{b) Effets sur l'ingestion et la digestion}

La première cause du ralentissement de la croissance provoqué par les aliments végétaux dépourvus de farine de poisson est la baisse de consommation d'aliment. Cet effet étant observé avec différents produits végétaux, il est probable qu'il soit dû à la fois à des substances indésirables apportées par les végétaux et à l'absence de composés stimulants présents dans la farine de poisson. C'est ce que suggèrent les résultats des études où 5 à $10 \%$ de produits marins sont maintenus dans le régime. Les connaissances sur les déterminants de la prise alimentaire sont très limitées chez les poissons. La diminution de l'appétit pourrait résulter de phénomènes orosensoriels (goût ou texture de l'aliment) ou de rétrocontrôles post-absorptifs; des recherches sont en cours sur ce sujet.

Chez les poissons, la digestibilité des protéines est généralement haute y compris celle des sources protéiques végétales (supérieure à 90\%; Glencross et al 2004, NRC 2011). Elle peut être réduite, comme celles des lipides, par des ANFs (facteurs anti-protéasiques, tannins) qui inhibent l'activité des enzymes digestives. Des perturbations de l'absorption des acides aminés et du glucose ont aussi été décrites chez la truite et la daurade nourries avec des aliments dont la totalité de la farine de poisson était remplacée par des ingrédients végétaux (Santigosa et al 2011).

\section{c) Effets métaboliques et conséquences sur les réserves corporelles}

Les effets métaboliques des aliments riches en végétaux et pauvres ou dépour- vus de farine de poisson sont très variables selon les substituts utilisés et les quantités incorporées. Selon les cas, les résultats des études ont aidé à améliorer les formules alimentaires en mettant en évidence les voies métaboliques perturbées : métabolisme azoté, glucidique, lipidique, minéral, etc. Les seuls effets qui se retrouvent dans tous les essais concernent les dépôts lipidiques et le cholestérol plasmatique.

La substitution de la farine de poisson par des mélanges d'ingrédients végétaux se traduit par une augmentation des dépôts adipeux périviscéraux même lorsque la croissance n'est pas modifiée (Panserat et al 2008, Torstensen et al 2011). L'origine de ce phénomène n'est pas encore connue. L'apport en acides aminés pourrait être impliqué dans la stimulation de la synthèse hépatique, mais l'orientation des dépôts plutôt vers la cavité abdominale que vers le muscle reste à expliquer.

Chez toutes les espèces, la substitution de la farine de poisson par des végétaux provoque une diminution du taux de cholestérol plasmatique (Kaushik et al 1995, Gómez-Requeni et al 2004). Cette baisse est vraisemblablement due à la fois à la diminution de l'apport en cholestérol par la farine de poisson et aux phytostérols apportés par les végétaux (Phillips et al 2002).

d) Effets sur la composition de la chair et ses qualités nutritionnelles et organoleptiques

Tant que le taux de croissance n'est pas modifié par la substitution, le changement de composition de l'aliment a peu d'effet sur les qualités organoleptiques du filet (de Francesco et al 2004 et 2007, Adamidou et al 2009). Toutefois, les pigments contenus dans certains végétaux peuvent affecter la pigmentation des salmonidés ; par exemple la lutéine du maïs donne une teinte jaune à la chair. La proportion d'AGPI n-6 dans la chair augmente avec la quantité de produits végétaux dans l'aliment, mais les modifications restent faibles si les lipides sont majoritairement apportés par de l'huile de poisson. D'après de Francesco et al (2004) la baisse de croissance résultant du remplacement total de la farine de poisson par des produits végétaux chez la truite est accompagnée d'une diminution du taux de lipides du muscle; la chair est alors plus ferme avec une odeur de poisson moins prononcée.

\section{e) Conséquences sur la santé des poissons}

Le tractus gastro-intestinal est le premier organe exposé à l'aliment. Son intégrité peut être affectée par les fibres présentes dans certaines sources protéiques végétales ou par d'autres ANFs pouvant avoir des effets synergiques (Knudsen et al 2007, Krogdalh et al 2010). Chez les salmonidés, les produits de soja altèrent l'intégrité des entérocytes et des muqueuses de l'intestin avec une augmentation des inflammations des couches inférieures (Van den Ingh et al 1996, Merrifield et al 2009). Le saumon atlantique se montre plus sensible que la truite pour un même taux d'incorporation (Refstie et al 2000). Les populations microbiennes intestinales sont aussi modifiées par les régimes contenant des végétaux, leur rôle dans les perturbations est soupçonné mais pas encore précisé (Merrifield et al 2009, Desai et al 2012).

Les études des mécanismes de défense immunitaire et des transcriptomes du foie et de l'intestin montrent chez toutes les espèces des modifications de marqueurs du système immunitaire lorsque la farine de poisson est substituée par des produits végétaux (Sitjà-Bobadilla et al 2005, Panserat et al 2009, Tacchi et al 2012). Cependant les conséquences sur la santé et la résistance des poissons aux pathogènes ne sont pas connues.

\section{3 / Substitution des huiles de poisson par des huiles végé- tales : pratiques actuelles, conséquences et limites}

La demande sans cesse croissante d'huile de poisson pour l'aquaculture a conduit vers la pénurie. Bien que les aliments aquacoles n'aient représenté, en 2008, que 4\% de l'ensemble des aliments pour les animaux produits dans le monde (24,2 Mt pour $708 \mathrm{Mt}$ d'aliment au total), l'aquaculture utilisait déjà $74 \%$ du stock d'huile de poisson disponible (FAO 2012). De plus en plus d'huiles de poisson sont maintenant produites à partir de déchets de l'industrie de transformation des poissons, mais cette production ne suffit pas à combler la hausse de la demande. Les autres sources d'AGPI-LC $\mathrm{n}-3$, elles aussi d'origine marine, sont disponibles sur le marché en quantités très limitées du fait soit des quotas de pêche instaurés pour prévenir leur épuisement (zooplancton), soit de difficultés de production à grande échelle (microalgues). La prise de conscience de la raréfaction des huiles marines a conduit à intensifier, depuis les années 2000, les recherches sur les effets de leur substitution par des huiles végétales.

\section{1 / Les caractéristiques des huiles végétales}

Les huiles de substitution ont été choisies principalement sur la base de leur disponibilité sur le marché mondial et de 
Tableau 4. Composition en acides gras d'huiles de poisson, de volaille et d'huiles végétales utilisées en alimentation aquacole (principaux acides gras en \% des acides gras totaux).

Source : NRC 2011.

\begin{tabular}{|c|c|c|c|c|c|c|c|}
\hline & \multicolumn{7}{|c|}{ Acides gras } \\
\hline & Saturés & $\begin{array}{c}\text { Mono- } \\
\text { Insaturés }\end{array}$ & $\begin{array}{c}\text { Acide } \\
\text { linoléique } \\
\text { C18:2 n-6 }\end{array}$ & $\begin{array}{c}\text { Acide } \\
\text { linolénique } \\
\text { C18:3 n-3 }\end{array}$ & $\begin{array}{c}E^{E P A}{ }^{(1)} \\
C 20: 5 n-3\end{array}$ & $\begin{array}{c}\mathrm{DHA}^{(2)} \\
\mathrm{C22}^{\mathrm{n}-3}\end{array}$ & $\begin{array}{c}\text { Ratio } \\
n-3 / n-6\end{array}$ \\
\hline Huiles de poisson & & & & & & & \\
\hline Anchois & 34,6 & 24,9 & 1,2 & 0,8 & 17,0 & 8,8 & 24 \\
\hline Capelan & 20,0 & 61,7 & 1,7 & 0,4 & 4,6 & 3,0 & 6,8 \\
\hline Foie de morue & 19,4 & 46,0 & 1,4 & 0,6 & 11,2 & 12,6 & 9,0 \\
\hline Menhaden & 33,3 & 24,8 & 1,3 & 0,3 & 12,6 & 9,1 & 16,7 \\
\hline Huile de volaille & 31,2 & 43,1 & 19,5 & 1,0 & I & I & 0,1 \\
\hline Huiles végétales & & & & & & & \\
\hline Colza & 7,4 & 62,3 & 20,2 & 12,0 & I & I & 0,6 \\
\hline Maïs & 13,3 & 24,2 & 58,0 & 0,7 & l & I & $\sim 0$ \\
\hline Lin & 9,4 & 20,2 & 12,7 & 53,3 & I & I & 4,2 \\
\hline Palme & 51,6 & 37,0 & 9,1 & 0,6 & l & I & $\sim 0$ \\
\hline Soja & 15,1 & 23,2 & 51,0 & 6,8 & I & I & 0,1 \\
\hline Tournesol & 10,6 & 19,5 & 65,7 & I & I & I & 0 \\
\hline
\end{tabular}

(1)EPA: acide eicosapentaénoïque ; ${ }^{(2)}$ DHA: acide docosahexaénoïque

leur composition en acides gras : huile de palme (50 Mt en 2010), de soja (40 Mt), de colza (19 Mt) et de tournesol (10 Mt) qui, ensemble, représentent plus de $80 \%$ du total des huiles végétales produites dans le monde ainsi que l'huile de lin produite en quantité plus limitée (moins de $1 \mathrm{Mt}$ ), mais riche en acide linolénique.

La composition en acides gras des huiles végétales est très différente de celle des huiles de poisson (tableau 4). Alors que les huiles de poisson sont caractérisées par leur forte teneur en AGPI-LC n-3, avec des proportions variables d'EPA et de DHA selon l'espèce de poisson dont elles sont issues, les huiles végétales en sont, toutes, totalement dépourvues. Certaines d'entre elles contiennent des quantités notables d'acide $\alpha$-linolénique ; c'est le cas de l'huile de colza (jusqu'à 12\%), et surtout de l'huile de lin (plus de 50\%). Toutes les huiles végétales contiennent des proportions élevées d'acides linoléique (C18:2 n-6) et oléique (C18:1 n-9), mais aussi d'acides gras saturés (acide palmitique 16:0 en particulier pour l'huile de palme).

Le rôle de pourvoyeur d'énergie peut être couvert par les différents types d'huiles avec une efficacité similaire même si certains acides gras semblent préférentiellement oxydés. La $\beta$-oxydation d'un acide gras est régulée principalement par sa concentration. La seule exception concerne le DHA qui est plus faiblement oxydé et donc retenu plus efficacement que les autres, probablement en raison de son rôle indispensable au maintien de l'intégrité des membranes cellulaires (Turchini et al 2007, BallesterLozano et al 2011).

\section{2 / Effets de la substitution des huiles de poisson par des huiles végétales}

Les premières études ont considéré les différentes huiles végétales individuellement. Les travaux plus récents sont conduits avec des mélanges d'huiles végétales dans l'objectif de rapprocher la composition des aliments alternatifs de ceux à base d'huile de poisson en termes de proportions des différentes classes d'acides gras (saturés, monoinsaturés, polyinsaturés n- 6 et n-3). Les résultats des nombreux travaux réalisés avec différents taux de substitution chez différentes espèces et souches de poissons ont été synthétisés dans un ouvrage (Turchini et al 2010). Les effets majeurs de la substitution des huiles de poisson par des huiles végétales sont dus à la différence de composition en acides gras. D'autres effets, plus mineurs, peuvent résulter du fait que l'huile de poisson contient de la vitamine $\mathrm{A}$, des pigments caroténoïdes et d'autres substances absentes des huiles végétales.

a) Conséquences sur la survie, la croissance et le métabolisme

Les poissons marins ne peuvent pas survivre en l'absence d'apport alimentaire en EPA et DHA. Chez les larves, la mortalité apparait rapidement en raison des faibles réserves (Tocher 2010).
Lorsque les essais sont réalisés chez des poissons de plus grande taille, on observe une baisse de la croissance et une déplétion des réserves en EPA et DHA (Parpoura et Alexis 2001, Izquierdo et al 2003) entraînant de sévères perturbations pouvant conduire à la mort des poissons (Le Boucher et al 2013) plus ou moins rapidement selon la quantité de réserves corporelles en AGPI-LC n-3 initiales. Des études chez le bar et la daurade montrent que les perturbations engendrées par la carence totale en EPA et DHA sont réversibles, avec une récupération très rapide des animaux dès lors qu'ils sont nourris avec un aliment apportant des AGPI-LC n-3 (Izquierdo et al 2005, Montero et al 2005, Le Boucher et al 2013).

Pour les espèces marines, le taux maximum de substitution de l'huile de poisson par des huiles végétales n'entraînant pas d'effets négatifs sur la croissance est de $80 \%$. Cette limite suggère que le besoin en AGPI-LC n-3, estimé pour le bar entre $0,7 \%$ (Geay et al 2011) et $0,88 \%$ de la ration (Parpoura et Alexis 2001), est sous-évalué pour une croissance optimale. Chez cette espèce, l'absence totale d'apport en AGPI-LC n-3 (substitution totale et concomitante d'huile et farine de poisson) induit bien une augmentation de l'expression du gène codant la $\Delta 6$-désaturase, mais la synthèse des AGPI-LC n-3 n'est pas effective. Des études récentes révèlent que la structure du promoteur de ce gène diffère entre le bar et les salmonidés (Geay et al 2012). Les auteurs avancent 
l'hypothèse que la capacité quasi inexistante du bar à synthétiser l'EPA et le DHA à partir de l'ALA est due à une perturbation de la régulation post-transcriptionnelle de la $\Delta 6$-désaturase.

Chez les salmonidés, plusieurs études ont démontré que la substitution totale de l'huile de poisson par des huiles végétales était possible sans impact sur la croissance tant que le régime contient au moins $20 \%$ de farine de poisson (Richard et al 2006, Drew et al 2007, Oo et al 2007). En revanche, lorsqu'il y a substitution conjointe et totale des farines et des huiles de poisson par des produits végétaux, la croissance est plus faible bien que la présence d'huile de lin dans le régime garantisse l'apport suffisant d'acide linoléique pour couvrir les besoins de la truite (Drew et al 2007, Panserat et al 2009). Ces résultats confirment que l'apport direct d'EPA et de DHA par l'alimentation est plus efficace que celui d'ALA car il permet d'économiser le coût de la synthèse.

Chez les salmonidés, l'expression des élongases et des désaturases qui permettent la synthèse d'EPA et de DHA est stimulée par l'apport alimentaire d'ALA et réprimée par l'apport d'EPA et de DHA (Seiliez et al 2001, Tocher et al 2001). D'ailleurs, l'augmentation de l'expression des désaturases chez la truite est aussi observée lorsque le contenu en EPA et DHA du régime est réduit, sans substitution par des huiles végétales (Kolditz et al 2008).

b) Conséquences sur la qualité des poissons

A teneur en lipides alimentaires identique, l'incorporation d'huiles végétales ne modifie ni le taux de lipides corporels des poissons ni leur teneur en lipides musculaires (Izquidero et al 2005, Richard et al 2006). En revanche, la composition en acides gras du poisson et en particulier de sa chair, est fortement affectée. Elle reflète globalement la composition en acides gras du régime, à l'exception du DHA pour lequel une relative conservation est observée chez les salmonidés comme chez les poissons marins (Turchini et al 2010). La chair des poissons nourris avec des régimes contenant des huiles végétales contient moins d'EPA et de DHA et davantage d'acides gras caractéristiques des huiles végétales incorporées (acide oléique, linoléique et linolénique). Chez les salmonidés, la déplétion est moins forte que chez les poissons marins en raison des capacités de synthèse. Cependant, si la synthèse endogène suffit à permettre la survie et la croissance des poissons, elle n'est pas suffisante pour compenser la diminution par l'apport alimentaire et maintenir des quantités élevées d'EPA et de DHA dans la chair.
Afin d'éviter que la chair de poisson ne perde son intérêt nutritionnel, la stratégie préconisée est l'utilisation d'un aliment de finition riche en huiles de poisson à haute teneur en DHA (tableau 4) afin de restaurer des niveaux élevés d'AGPI-LC n-3 et de diminuer le contenu en acides gras caractéristiques des huiles végétales, l'acide linoléique C18:2 n-6 notamment, avant la commercialisation (Corraze et Kaushik 2009). La figure 3 montre un exemple de cette plas- ticité de la composition de la chair chez le saumon. Les résultats des nombreuses études réalisées sur ce sujet ont permis d'élaborer des modèles de prédiction du contenu en acides gras de la chair des poissons en fonction de leur poids et vitesse de croissance, de la composition des lipides du régime et de la durée des phases de substitution et de finition (Robin et Skalli 2007, Ballester-Lozano et al 2011, BenitoPalos et al 2011).

Figure 3. Effets d'Aliments (A) contenant de l'Huile de Poisson (HP) ou de l'Huile de Colza $(H C)$ en remplacement de l'huile de poisson (taux de substitution : HP = 0\%, $25 \mathrm{HC}=25 \%, 50 \mathrm{HC}=50 \%, 100 \mathrm{HC}=100 \%)$ sur les acides gras du muscle du saumon: (B) après 16 semaines d'alimentation; (C) après 12 semaines d'une alimentation à base d'huile de poisson. Cette alimentation de finition permet de diminuer les proportions de C18:2 n-6 et de restaurer celles d'EPA et de DHA (\% acides gras totaux) (d'après Bell et al 2003).

\section{A - Acides gras des aliments}

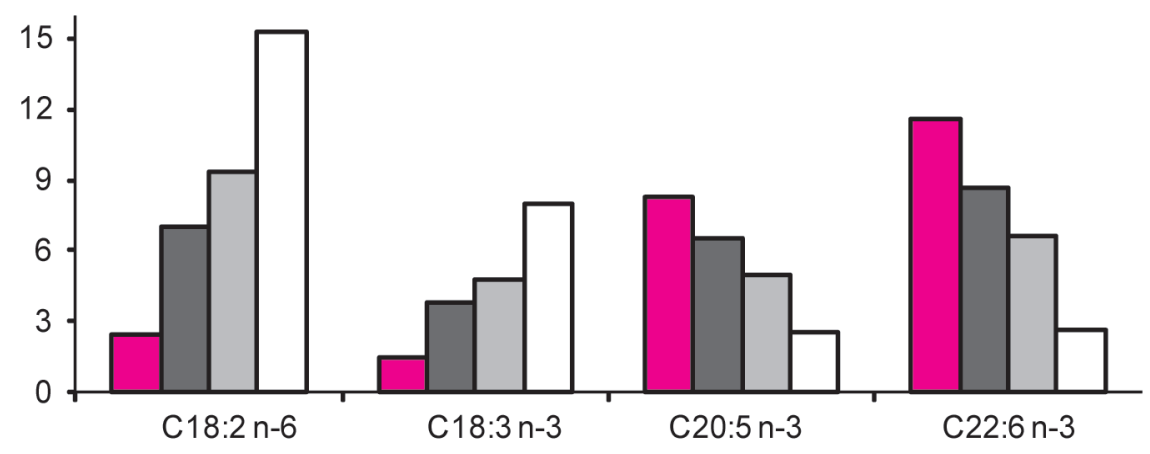

B - Acides gras du muscle après 16 semaines d'alimentation

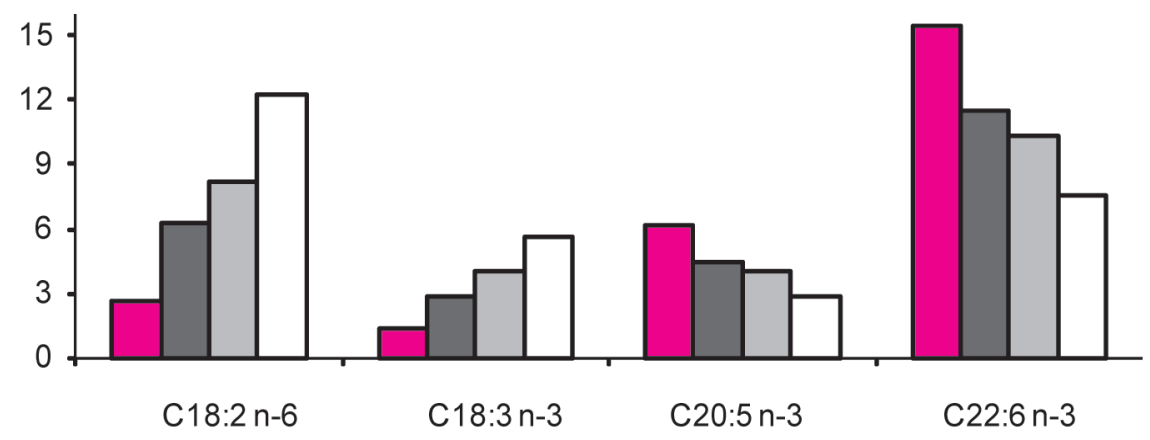

C - Acides gras du muscle après 12 semaines de finition avec HP

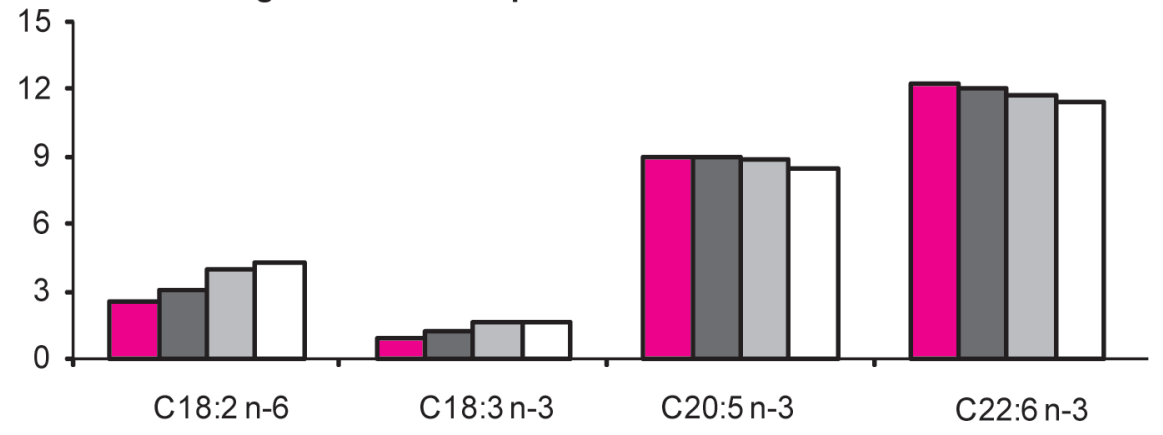


Les modifications de composition en acides gras de la chair des poissons n'ont pas de répercussion notable sur ses qualités organoleptiques. Il n'y a pas de différence significative des descripteurs sensoriels (aspect, odeur, flaveur, texture) mise en évidence par les jurys d'évaluation, quelle que soit l'espèce, même lorsque la substitution est totale (Regost et al 2003, Corraze et al 2004, Izquierdo et al 2003 et 2005, Torstensen et al 2005).

En termes de qualité sanitaire, la substitution présente un intérêt. Les huiles de poisson (et dans une moindre mesure les farines) contiennent souvent des Polluants Organiques Persistants (POP), présents dans les populations sauvages exploitées par la pêche minotière. Ces contaminants, apportés par l'aliment, s'accumulent dans la chair des poissons. La substitution par des huiles végétales, moins contaminées, permet de diminuer la teneur en POP de la chair (Bell et al 2005, Oo et al 2007). En cas d'alimentation de finition avec un régime riche en huile de poisson, les niveaux de POP ré-augmentent, mais sans atteindre ceux des poissons nourris avec des aliments à base d'huile de poisson pendant tout le cycle d'élevage (Bell et al 2005, Berntssen et al 2010).

\section{c) Effets sur le métabolisme du cholesté- rol}

La substitution des huiles de poisson par des huiles végétales affecte le métabolisme du cholestérol. Des analyses transcriptomiques montrent une augmentation de l'expression des enzymes impliquées dans la synthèse du cholestérol (24-dehydrocholesterol reductase notamment) dans le foie de saumons, de truites et de bars nourris avec des aliments à base d'huiles végétales (Leaver et al 2008, Panserat et al 2008, Geay et al 2011). Cependant, la synthèse endogène ne suffit pas à compenser la diminution de l'apport par voie alimentaire. On observe une baisse du taux de cholestérol dans le plasma des poissons, d'autant plus importante que le taux de remplacement est élevé (Richard et al 2006, Panserat et al 2008, Turchini et al 2010). Lorsqu'il y a substitution concomitante de l'huile et de la farine de poisson par des produits végétaux, les effets se cumulent et la baisse du cholestérol circulant est encore plus marquée. L'hypocholestérolémie ne semble pas perturber la santé des poissons ; toutefois, des études à long terme sont nécessaires pour confirmer l'absence d'effets négatifs.

d) Conséquences sur la santé des poissons Les conséquences de la substitution des huiles de poisson par des huiles végétales sur la santé des poissons sont souvent évoquées mais les connaissances à ce sujet sont limitées. Dans une synthèse bien documentée, Montero et Izquidero (2010) montrent que, dans les conditions où les besoins en AGPI-LC n-3 sont couverts, les effets de la substitution sur la santé des poissons peuvent être positifs, négatifs ou absents sans qu'il soit encore possible de tirer des lois générales.

Comme dans le cas du remplacement des farines de poisson par des sources protéiques végétales, c'est au niveau du tube digestif que des perturbations sont le plus souvent observées lorsque la substitution de l'huile de poisson est supérieure à 60-80\%. Le renouvellement rapide des entérocytes les rend sensibles aux changements de la composition de leur membrane cellulaire qui est affectée par la composition en acides gras de l'aliment. Par exemple, chez le saumon, le remplacement de l'huile de poisson par des huiles végétales affecte la perméabilité épithéliale, mais aussi les populations microbiennes intestinales et la réponse immunitaire après exposition à un pathogène. Plusieurs études montrent des modifications des marqueurs du système immunitaire chez différentes espèces, mais les conséquences sur la santé et la résistance des poissons aux pathogènes ne sont pas connues (Montero et Izquidero 2010).

\section{4 / Impact environnemental de la substitution des produits halieutiques dans l'alimenta- tion des poissons d'élevage}

Si la substitution des farines et huiles de poisson par des ingrédients végétaux permet d'atteindre son objectif de diminuer la pression sur les ressources naturelles marines, il est nécessaire de considérer l'impact environnemental des aliments constitués de ressources végétales. En effet, il convient d'éviter que l'amélioration de certaines caractéristiques environnementales se fasse au détriment de certaines autres. Dans ce but, les approches basées sur les caractéristiques nutritionnelles des aliments et leurs effets sur le poisson sont maintenant accompagnées d'études scientifiques sur l'impact environnemental des différentes formulations, s'appuyant sur l'Analyse du Cycle de Vie (ACV).

L'ACV a montré sa pertinence comme méthode multicritère d'évaluation des performances environnementales des systèmes agricoles (Van der Werf et Petit 2002). C'est une méthode normalisée (ISO 2006a et b) qui permet de comptabiliser l'ensemble des ressources utilisées et des matières polluantes émises par un système de production, depuis l'extraction des matières premières jusqu'à la fin de vie des produits (Guinée et al 2002). Depuis dix ans, cette méthode est appliquée à l'aquaculture et à la pêche (Papatryphon et al 2004, Pelletier et al 2007, Aubin 2013). Les principales catégories d'impact potentiel analysées pour évaluer les activités piscicoles sont : l'eutrophisation ( $\mathrm{kg}$ éq. $\left.\mathrm{PO}_{4}\right)$, le changement climatique (kg éq. $\mathrm{CO}_{2}$ ), l'acidification ( $\mathrm{kg}$ éq. $\mathrm{SO}_{2}$ ), l'utilisation d'énergie (MJ), l'utilisation de production primaire nette $(\mathrm{kg} \mathrm{C})$, l'utilisation de surface terrestre $\left(\mathrm{m}^{2}\right)$ et l'écotoxicité terrestre (kg éq. 1,4 DN). Elles sont calculées selon des modèles validés, principalement avec la méthode CML2 (Guinée et al 2002), mais certaines ont été produites spécifiquement pour l'aquaculture comme l'utilisation de production primaire nette (UPPN, Papatryphon et al 2004). La réalisation des ACV nécessite le recours à des bases de données à la fois précises, fiables et complètes pour couvrir l'ensemble des processus des systèmes de production (écloserie, fabrication des aliments, fourniture d'énergie, transport...). Pour évaluer la substitution des ressources d'origine halieutique par des ingrédients végétaux, il a été nécessaire de caractériser les différentes cultures végétales et les produits aquatiques entrant dans la composition des aliments piscicoles.

Les premières évaluations environnementales des systèmes aquacoles réalisées avec la méthode ACV ont montré que la majorité des impacts environnementaux étaient générés par la production et la valorisation des aliments au sein du système de production (Aubin et al 2009).

Pour illustrer la démarche, nous présentons des résultats obtenus dans le cadre du programme européen « Aquamax ». Afin d'analyser l'effet d'une substitution partielle $(66 \%)$ de l'huile de poisson par un mélange d'huiles végétales dans l'aliment de daurades en phase de grossissement, les performances de deux régimes alimentaires couvrant les besoins nutritionnels des daurades et ayant des caractéristiques identiques en termes de teneurs en protéines, lipides et énergie (tableau 5) ont été comparées. Les régimes se différenciaient par la nature des huiles : l'aliment «standard» contenait $18,2 \%$ d'huile de poisson, le régime avec substitution par des huiles végétales (HV66) contenait seulement $6,1 \%$ d'huile de poisson, les huiles végétales constituant $66 \%$ de l'ensemble des huiles de ce régime. Il faut noter que les deux aliments contenaient $20 \%$ de farine et d'hydrolysat de poisson, le reste des protéines étant apportées par du gluten de maïs et du tourteau de soja. 
Tableau 5. Composition (\%) de l'aliment standard ou substitué en huiles végétales (HV66) utilisé pour la comparaison des performances zootechniques et environnementales chez la daurade pendant la phase de grossissement et origine des ingrédients.

\begin{tabular}{|l|c|c|l|}
\hline Ingrédients & Standard & HV66 & \multicolumn{1}{|c|}{ Origine } \\
\hline Gluten de Maïs & 37,9 & 37,9 & Europe de l'Est \\
Huile de poisson & 18,2 & 6,1 & Pérou \\
Huile de lin & & 7,0 & Allemagne \\
Huile de palme & & 3,0 & Malaisie \\
Huile de colza & & 2,1 & Europe de l'Est \\
Farine de poisson & 15,0 & 15,0 & Pérou \\
Tourteau de soja & 14,0 & 14,0 & Brésil \\
Hydrolysat de poisson & 5,0 & 5,0 & Chili \\
Blé & 4,0 & 4,1 & Europe de l'Est \\
Monocalcium phosphate & 2,0 & 2,0 & Norvège \\
Lecithine de Soja & 1,5 & 1,0 & Brésil ; Extraction : Danemark \\
Premix minéraux \& vitamines & 1,0 & 0,75 & Grèce \\
Lysine & 0,8 & 0,55 & France \\
Eau & 0,6 & 1,5 & \\
\hline Composition & & & \\
\hline Humidité (\% frais) & 9,1 & 9,1 & \\
Protéine (\% MS) & 46 & 46 & \\
Lipides (\% MS) & 21 & 21 & \\
\hline
\end{tabular}

\section{MS : Matière Sèche}

L'essai d'alimentation, supervisé par le «Hellenic Centre for Marine Research», a duré 485 jours. Le poids moyen individuel final était de $379 \mathrm{~g}$ pour les daurades nourries avec le régime standard et de $405 \mathrm{~g}$ pour celles nourries avec le régime HV66. L'efficacité de conver-

sion alimentaire a été semblable avec les deux régimes. La figure 4 montre les profils environnementaux relatifs aux deux traitements alimentaires. Les résultats sont exprimés sur la base d'une tonne de daurade produite à la sortie de la ferme.

Figure 4. Profils environnementaux relatifs des lots de daurade élevés avec l'aliment standard ou l'aliment substitué à $66 \%$ avec des huiles végétales.

UPPN : Utilisation de la production primaire nette.

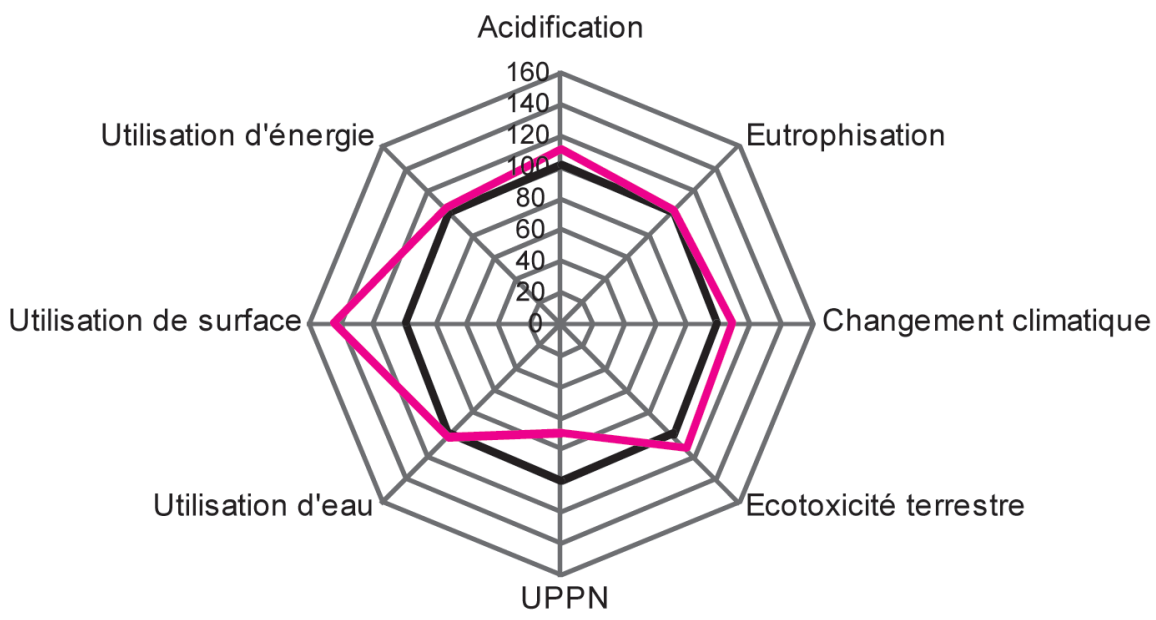

- Scénario standard — Scénario $66 \% \mathrm{HV}$
Les résultats de l'ACV intégrant l'ensemble des processus du système de production et les données de l'expérimentation indiquent des performances environnementales très proches pour les catégories eutrophisation, changement climatique, utilisation d'énergie et d'eau, et acidification, montrant que l'impact environnemental de la pêche et de l'extraction de l'huile de poisson est, à ce niveau de substitution, complètement remplacé par les impacts associés à la culture et à la production des huiles végétales. Cette substitution a bien eu un effet bénéfique sur 1'utilisation de production primaire nette $(-25 \%)$ traduisant une moindre pression sur les ressources biotiques, en particulier halieutiques. En revanche, on observe une augmentation importante de l'utilisation de surface terrestre $(+45 \%)$ correspondant aux surfaces agricoles nécessaires pour produire les ingrédients de la ration, ce qui pourrait, à terme, placer l'aquaculture sur le même rang que les autres productions animales dans la compétition pour l'usage des terres. D'après l'étude de Boissy et al (2011) sur le saumon, la substitution totale des huiles de poisson par des huiles végétales amplifie encore ce phénomène et dégrade aussi l'impact écotoxicité terrestre.

\section{Conclusions et perspectives}

Comme l'illustre la figure 5, les résultats de la recherche internationale dans le domaine de la nutrition des poissons ont été utilisés par l'industrie pour faire fortement évoluer la composition des aliments aquacoles. Les farines et huiles de poisson ne représentent plus qu'un quart du régime des salmonidés et des poissons marins. Les ingrédients végétaux sont maintenant devenus majoritaires dans les régimes de toutes les espèces aquacoles. Cependant, pour que les salmonidés et les poissons marins d'élevage soient producteurs nets de poisson, c'est-à-dire que la quantité de poisson produite soit supérieure à la quantité de poisson nécessaire pour les nourrir, la substitution doit être poursuivie. Les derniers résultats de la recherche suggèrent qu'il est possible de réduire à environ 5 à $10 \%$ (selon les espèces) la quantité de ressources marines dans l'alimentation des poissons de haut niveau trophique sans effets délétères. Le remplacement total n'est pas encore possible sans altérer la survie et les performances des poissons. Des progrès ont été réalisés pour améliorer les apports azoté et énergétique et la biodisponibilité des nutriments. Des recherches sont encore nécessaires sur les ANFs et leurs relations avec la microflore intestinale, sur l'origine des perturbations de l'appétit et sur les minéraux dont l'apport pourrait être optimisé. 
Figure 5. Evolution de la composition des aliments utilisés pour élever le saumon, la truite et les poissons marins de 1995 à 2011 (source : Fabricants d'aliments Le Gouessant et BioMar France).

Les chiffres entre parenthèses représentent les teneurs moyennes en protéines/lipides du régime (\% de la matière sèche). FP : Farine de Poisson, HP : Huile de Poisson, PAT : Produits Animaux Transformés, HV : Huiles Végétales, Autres : produits végétaux.

\section{A - 1995}

Saumon $(42 / 25)$

Truite (42/22)

P. marins $(45 / 18)$

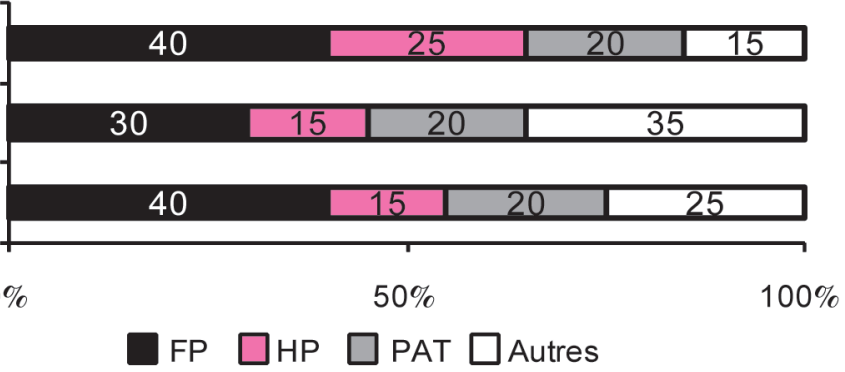

B - 2001

Saumon $(40 / 28)$

Truite (42/24)

P. marins $(45 / 20)$

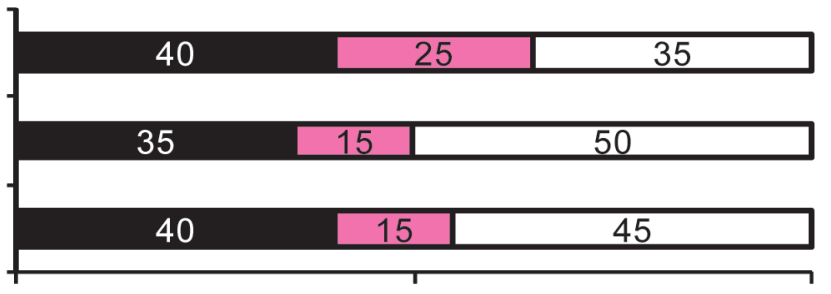

$0 \%$

$50 \%$

$100 \%$

FP $\square$ HP $\square$ Autres

\section{C - 2006}

Saumon (38/35)

Truite (40/26)

P. marins $(43 / 22)$

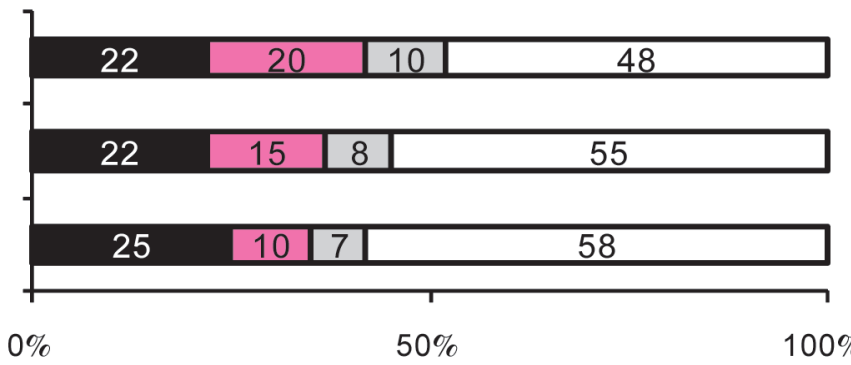

FP $\square$ HP $\square$ HV $\square$ Autres

D - 2011

Saumon (36/35)

Truite (38/30)

P. marins $(40 / 20)$

1

$$
-
$$

\begin{tabular}{l|l|l|}
12 & 12 & 18 \\
\hline
\end{tabular}

L

58

\begin{tabular}{|l|l|l|l|l|}
\hline 10 & 10 & 15 & 65 \\
\hline \multicolumn{4}{|c|}{} \\
\hline 15 & 10 & 10 & & 65 \\
\hline
\end{tabular}

$0 \%$

$50 \%$

$100 \%$
Des alternatives complémentaires aux végétaux sont envisagées : l'utilisation dans les aliments aquacoles de protéines issus de porc et de poulet vient d'être autorisée au niveau européen comme ailleurs dans le monde. Bien qu'actuellement les réticences au niveau français soient fortes pour des questions d'image des produits, ces ingrédients pourraient permettre de limiter les effets négatifs du remplacement de la farine de poisson sur les poissons et sur l'impact environnemental dû à l'usage des végétaux. D'autres sources de protéines telles que les farines de larves d'insectes sont aussi testées. Si leur qualité nutritionnelle et sanitaire s'avère satisfaisante, il faudra ensuite trouver les conditions pour qu'elles soient produites en quantités suffisantes pour répondre à la demande et s'assurer des performances économiques et environnementales des aliments qui en contiendront.

L'absence d'apport alimentaire d'EPA et de DHA n'est pas possible chez les poissons marins pour des raisons biologiques. Chez les autres espèces leur suppression diminue fortement la valeur nutritionnelle de la chair alors que les produits aquatiques sont les principaux vecteurs d'AGPI-LC n-3 dans l'alimentation humaine. La fourniture d'EPA et de DHA est un enjeu important de santé publique en raison de leur rôle dans le développement cérébral et dans la protection contre les accidents cardiovasculaires. Si de nombreuses alternatives à la farine de poisson peuvent être envisagées, il n'en va pas de même pour les huiles de poisson. Il n'y a pas à l'heure actuelle d'autres sources d'AGPI-LC n-3 disponibles en quantité notable. Une des pistes explorées est la production d'EPA et de DHA par des organismes génétiquement modifiés (microorganismes et végétaux tels que la cameline, une Brassicacée riche en ALA). Si cette production devient possible, se posera alors la question de l'acceptabilité des produits d'animaux nourris avec des huiles issues d'OGM. Une autre piste explorée est la production de microalgues riches en AGPI-LC n-3 notamment en DHA comme «Isochrysis galbana». La limite actuelle est la quantité produite et le coût qui rend ces microalgues inabordables pour l'alimentation animale.

Enfin, en parallèle des recherches concernant la nutrition pour faire encore évoluer les formules alimentaires, des travaux ont été entrepris pour identifier, dans les populations de poissons d'élevage, des individus mieux adaptés que d'autres pour utiliser efficacement les aliments à base de végétaux. Les premiers résultats de ces recherches sont relatés dans l'article de Le Boucher et al (2013, ce numéro). 


\section{Références}

Adamidou S., Nengas I., Henry M., Grigorakis K., Rigos G., Nikolopoulou D., Kotzamanis Y., Bell G.J., Jauncey K., 2009. Growth, feed utilization, health and organoleptic characteristics of European seabass (Dicentrarchus labrax) fed extruded diets including low and high levels of three different legumes. Aquaculture, 293, 263-271.

Alami-Durante H., Médale F., Cluzeaud M., Kaushik S.J., 2010. Skeletal muscle growth dynamics and expression of related genes in white and red muscles of rainbow trout fed diets with graded levels of a mixture of plant protein sources as substitutes for fishmeal. Aquaculture, 303, 50-58.

Aubin J., 2013. Life Cycle Analysis as applied to environmental choices regarding farmed or wildcaught fish, CAB Reviews, 8 , $1-10$

Aubin J., Papatryphon E., van der Werf H.M.G., Chatzifotis S., 2009. Assessment of the environmental impact of carnivorous finfish production systems using life cycle assessment. J. Clean Prod., 17, 354-361.

Ballester-Lozano G.F., Benito-Palos L., Navarro J.C., Kaushik S., Pérez-Sánchez J., 2011. Prediction of fillet fatty acid composition of market-size gilthead sea bream (Sparus aurata) using a regression modelling approach Aquaculture, 319, 81-88.

Bell J.G., McGhee F., Campbell P.J., Sargent J.R., 2003. Rapeseed oil as an alternative to marine fish oil in diets of post-smolt Atlantic salmon (Salmo salar): changes in flesh fatty acid composition and effectiveness of subsequent fish oil «wash out». Aquaculture, 218, 515528.

Bell J.G., McGhee F., Dick J.R., Tocher D.R., 2005. Dioxin and dioxin-like polychlorinated biphenyls (PCBs) in Scottish farmed salmon (Salmo salar): effects of replacement of dietary marine fish oil with vegetable oils. Aquaculture, 243, 305-314.

Benito-Palos L., Bermejo-Nogales A., Karampatos A.I., Ballester-Lozano G.F., Navarro J.C., Diez A., Bautista J.M., Bell J.G., Tocher D.R., Obach A., Kaushik S., PérezSánchez J., 2011. Modelling the predictable effects of dietary lipid sources on the fillet fatty acid composition of one-year-old gilthead sea bream (Sparus aurata L.). Food Chem., 124, 538-544.

Berntssen M.H.G., Julshamn K., Lundebye A.K., 2010. Chemical contaminants in aquafeeds and Atlantic salmon (Salmo salar) following the use of traditional- versus alternative feed ingredients. Chemosphere, 78, 637-646.

Boissy J., Aubin J., Drissi A., van der Werf H.M.G., Bell G.J., Kaushik S.J., 2011. Environmental impacts of plant-based salmonid diets at feed and farm scales. Aquaculture, 321, 61-70.

Borges P., Médale F., Dias J., Valente L., 2012. Protein utilisation and intermediary metabolism of Senegalese sole as a function of Protein/Lipid ratio. Br. J. Nutr., 109, 13731381.

Cao L., Wang W., Yang C., Yang Y., Diana J., Yakupitiyage A., Luo Z., Li D., 2007. Application of microbial phytase in fish feed. Enz. Microbial Technol., 40, 497-507.
Collins S.A., Overland M., Skrede A., Drew M.D., 2013. Effect of plant protein sources on growth rate in salmonids: Meta-analysis of dietary inclusion of soybean, pea and canola/ rapeseed meals and protein concentrates. Aquaculture, 400, 85-100.

Corraze G., Kaushik S., 2009. Nutrition lipidique et remplacement de l'huile de poisson par des huiles végétales en pisciculture. Cah. Agric., 18, 113-118.

Corraze G., Radunz-Neto J., Richard N., Cardinal M., Kaushik S., 2004. Remplacement de l'huile de poisson par des huiles végétales chez la truite arc-en-ciel : incidence sur les qualités nutritionnelles et organoleptiques. Viandes et Produits Carnés (HS), 115-116.

De Francesco M., Parisi G., Médale F., Lupi P., Kaushik S., Poli B.M., 2004. Effect of long-term feeding with a plant protein mixture based diet on growth and body/ fillet quality traits of large rainbow trout (Oncorhynchus mykiss). Aquaculture, 236, 413-429.

De Francesco M., Parisi G., Perez-Sanchez J., Gomez-Requeni P., Médale F., Kaushik S.J., Mecatti M., Poli B.M., 2007. Effect of highlevel fish meal replacement by plant proteins in gilthead sea bream (Sparus aurata) on growth and body/fillet quality traits. Aquacult. Nutr., $13,361-372$.

Desai A.R, Links M.G., Collins S.A., Mansfield G.S., Drew M.D., Van Kessel A.G., Hill J.E., 2012. Effects of plant-based diets on the distal gut microbiome of rainbow trout (Oncorhynchus mykiss). Aquaculture, 350, 134-142.

Drew M.D., Ogunkoya A.E., Janz D.M., Van Kessel A.G., 2007. Dietary influence of replacing fish meal and oil with canola protein concentrate and vegetable oils on growth performance, fatty acid composition and organochlorine residues in rainbow trout (Oncorhynchus mykiss). Aquaculture, 267, 260-268.

Dupont-Nivet M., Médale F., Leonard J., Le Guillou S., Tiquet F., Quillet E., Geurden I., 2009. Evidence of genotype-diet interactions in the response of rainbow trout (Oncorhynchus mykiss) clones to a diet with or without fishmeal at early growth. Aquaculture, 295, 15-21

Enes P., Panserat S., Kaushik S., Oliva-Teles A., 2011. Dietary carbohydrate utilization by European sea bass (Dicentrarchus labrax L.) and gilthead sea bream (Sparus aurata L.) juveniles. Rev. Fish. Sci., 19, 201-215.

FAO, 2012. La situation mondiale des pêches et de l'aquaculture 2012. Rome. 241p (http://www.fao.org/docrep/016/i2727f/i2727f $\underline{00 . h t m)}$

Francis G., Makkar H. P. S., Becker K., 2001. Antinutritional factors present in plantderived alternate fish feed ingredients and their effect in fish. Aquaculture, 199, 197-227.

Geay F., Ferraresso S., Zambonino-Infante J.-L., Bargelloni L., Quentel C., Vandeputte M., Kaushik S., Cahu C.L., Mazurais D., 2011. Effects of the total replacement of fish-based diet with plant-based diet on the hepatic transcriptome of two European sea bass (Dicentrarchus labrax) half-sib families showing different growth rates with the plant-based diet. BMC Genomics, 12, 522.
Geay F., Zambonino-Infante J.-L., Reinhardt R., Kuhl H., Santigosa E., Cahu C., Mazurais D., 2012. Characteristics of fads2 gene expression and putative promoter in European sea bass (Dicentrarchus labrax): Comparison with salmonid species and analysis of CpG methylation. Mar. Genom., 5, 7-13.

Glencross B.D., Carter C.G., Duijster N., Evans D.R., Dods K., McCafferty P., Hawkins W.E., Maas R., Sipsas S., 2004. A comparison of the digestibility of a range of lupin and soybean protein products when fed to either Atlantic salmon (Salmo salar) or rainbow trout (Oncorhynchus mykiss). Aquaculture, 237, 333-346.

Gómez-Requeni P., Mingarro M., CalduchGiner J.A., Médale F., Martin S.A.M., Houlihan D.F., Kaushik S., Pérez-Sánchez J., 2004. Protein growth performance, amino acid utilisation and somatotropic axis responsiveness to fish meal replacement by plant protein sources in gilthead sea bream (Sparus aurata). Aquaculture, 232, 493-510.

Green J.A., Hardy R.W., 2002. The optimum dietary essential amino acid pattern for rainbow trout (Oncorhynchus mykiss), to maximize nitrogen retention and minimize nitrogen excretion. Fish Physiol. Biochem., 27, 97-108.

Guinée J.B., Gorrée M., Heijungs R., Huppes G., Kleijn R., de Koning A., van Oers L., Wegener Sleeswijk A., Suh S., Udo de Haes H.A., de Bruijn H., van Duin R., Huijbregts M.A.J., 2002. Handbook on life cycle assessment. An operational guide to the ISO standards. Kluwer Academic Publishers, Dordrecht, The Netherland, 692p.

Hertrampf J.W., Pieded-Pascual F., 2000. Handbook on ingredients for Aquaculture Feeds. Kluwer Academic Publishers, Dordrecht, Boston, London, 573p.

ISO, 2006a. Principles and Framework. In: Management E. (Ed), Life Cycle Assessment European Commitee for Standardization, Brussels, pp20.

ISO, 2006b. Requirements and guidelines In: Management E. (Ed), Life Cycle Assessment. European Commitee for Standardization, Brussels, pp20.

Izquierdo M.S., Obach A., Arantzamendi L., Montero D., Robaina L., Rosenlund G., 2003. Dietary lipid sources for seabream and seabass: growth performance, tissue composition and flesh quality. Aquacult. Nutr., 9, 397-407.

Izquierdo M., Montero D., Robaina L., Caballero M., Rosenlund G., Gines R., 2005. Alterations in fillet fatty acid profile and flesh quality in gilthead seabream (Sparus aurata) fed vegetable oils for a long term period. Recovery of fatty acid profiles by fish oil feeding. Aquaculture, 250, 431-444.

Kaushik S.J., Cravedi J.P., Lalles J.P., Sumpter J., Fauconneau B., Laroche M. 1995. Partial or total replacement of fish meal by soybean protein on growth, protein utilization, potential estrogenic or antigenic effects, cholesterolemia and flesh quality in rainbow trout, (Oncorhynchus mykiss). Aquaculture, 133, 257-274.

Knudsen D., Uran P., Arnous A., Koppe W., Frokler H., 2007. Saponin-containing subfractions of soybean molasses induce enteritis in the distal intestine of Atlantic salmon. J. Agric. Food Chem., 55, 2261-2267. 
Kolditz C.I., Paboeuf G., Borthaire M.J., Esquerré D., SanCristobal M., Lefèvre F. Médale F., 2008. Changes induced by dietary energy intake and divergent selection for muscle fat content in rainbow trout (Oncorhynchus mykiss), assessed by transcriptome and proteome analysis of the liver. BMC Genomics, 9, 506 .

Krogdahl A., Penn M., Thorsen J., Refstie S., Bakke A.M., 2010. Important antinutrients in plant feedstuffs for aquaculture: an update on recent findings regarding responses in salmonids. Aquacult. Res., 41, 333- 344.

Le Boucher R., Dupont-Nivet M., Vandeputte M., Kerneïs T., Goardon L., Labbé L., Chatain B., Médale F., Quillet E., 2012. Selection for adaptation to dietary shifts: towards sustainable breeding of carnivorous fish. Plos One, 7, e44898.

Le Boucher R., Vandeputte M., DupontNivet M., Quillet E., Ruelle F., Vergnet A., Kaushik S., Allamellou J. M., Médale F., Chatain B., 2013. Genotype by diet interactions in European sea bass (Dicentrarchus labrax L.): Nutritional challenge with totally plant-based diets. J. Anim. Sci., 91, 44-56.

Le Boucher R., Dupont-Nivet M., Laureau S., Labbé L., Geurden I., Médale F., Chatain B., Vandeputte M., Quillet E., 2013. Amélioration génétique et utilisation des aliments à base de végétaux en pisciculture. INRA Prod. Anim., 26, 4, 317-326.

Leaver M.J., Villeneuve L.A.N., Obach A., Jensen L., Bron J.E., Tocher D.R., Taggart J.B., 2008. Functional genomics reveals increased cholesterol and highly unsaturated fatty acid biosynthesis after dietary substitution of fish oil with vegetable oils in Atlantic salmon (Salmo salar). BMC Genomics, 9, 299.

Mambrini M., Guillaume J., 1999. Nutrition protéique. Guillaume J., Kaushik S., Bergot P., Métailler R. (Eds), Nutrition des poissons et des crustacés, INRA, Paris, France, 113-146.

Médale F., Guillaume J.C., 1999. Nutrition énergétique. In : Nutrition des poissons et des crustacés. Guillaume J., Kaushik S., Bergot P., Métailler R. (Eds). INRA, Paris, France, 87111.

Médale F., Kaushik S., 2009. Les sources protéiques dans les aliments pour les poissons d'élevage. Cah. Agric., 18, 103-111.

Merrifield D. L., Dimitroglou A., Bradley G., Baker R.T.M., Davies S.J., 2009. Soybean meal alters autochthonous microbial populations, microvilli morphology and compromises intestinal enterocyte integrity of rainbow trout, (Oncorhynchus mykiss) (Walbaum). J. Fish Diseases, 32, 755-766.

Montero D., Izquierdo M.S., 2010. Health and welfare of fish fed vegetable oils as alternative lipid sources to fish oil. Turchini G.M., Ng W.K., Tocher D.R. (Eds). Fish oil replacement and alternative lipid sources in aquaculture feeds. CRC Press, USA, 439-485.

Montero D., Robaina L., Caballero M.J. Ginés R., Izquierdo M.S., 2005. Growth, feed utilization and flesh quality of European sea bass (Dicentrarchus labrax) fed diets containing vegetable oils: A time-course study on the effect of a re-feeding period with a $100 \%$ fish oil diet. Aquaculture, 248, 121-134.
Nakari T., Erkomaa K., 2003. Effects of phytosterols on zebrafish reproduction in multigeneration test. Environ. Pollut. 123, 267-273.

Naylor R.L., Hardy R.W., Bureau D.P., Chiu A., Elliott M., Farrell A.P., Forster I., Gatlin D.M., Goldburg R.J., Hua K., Nichols P.D., 2009. Feeding aquaculture in an era of finite resources. P. Natl. Acad. Sci. USA 106, 1510315110.

NRC (National Research Council), 2011. Nutrition Requirements of Fish, Washington D.C., USA, National Academy Press, 373p.

Oo A.N., Satoh S., Tsuchida N., 2007. Effect of replacements of fishmeal and fish oil on growth and dioxin contents of rainbow trout. Fisheries Sci., 73, 750-759.

Panserat S., Kolditz C., Richard N., PlagnesJuan E., Piumi F., Esquerré D., Médale F., Corraze G., Kaushik S., 2008. Hepatic gene expression profiles in juvenile rainbow trout (Oncorhynchus mykiss) fed fish meal or fish oil free diets. Br. J. Nutr., 100, 953-967.

Panserat S., Hortopan G.A., Plagnes-Juan E., Kolditz C., Lansard M., Skiba-Cassy S., Esquerré D., Geurden I., Médale F., Kaushik S., Corraze G., 2009. Differential gene expression after total replacement of dietary fish meal and fish oil by plant products in rainbow trout (Oncorhynchus mykiss) liver. Aquaculture, 294, 123-131.

Panserat S., Kaushik S., Médale F., 2013. Rainbow trout as a model for nutrition and nutrient metabolism studies. In: Trout: from physiology to conservation. Polakof S., Moon T.W. (Eds). Nova Science Publishers, 131-153.

Papatryphon E., Petit J., Kaushik S.J., van der Werf H.M.G., 2004. Environmental impact assessment of salmonid feeds using Life Cycle Assessment (LCA). Ambio, 33, 316-323.

Parpoura A.C.R., Alexis M.N., 2001. Effects of different dietary oils in sea bass (Dicentrarchus labrax) nutrition. Aquacult. Int., 9, 463-476.

Pelletier N.L., Ayer N.W., Tyedmers P.H., Kruse S.A., Flysjo A., Robillard G., Ziegler F., Scholz A.J., Sonesson U., 2007. Impact categories for life cycle assessment research of seafood production systems: Review and prospectus. Int. J. Life Cycle Assess., 12, 414421.

Phillips K.M., Ruggio D.M., Toivo J.I., Swank M.A., Simpkins A.H., 2002. Free and esterified sterol composition of edible oils and fats. J. Food Comp. Anal., 15, 123-142.

Polakof S., Panserat S., Soengas J., Moon T.W., 2012. Glucose metabolism in fish: a review. J. Comp. Physiol. B, 182, 1015-1045.

Refstie S., Korsøen Ø.J., Storebakken T., Baeverfjord G., Lein I., Roem A.J., 2000. Differing nutritional responses to dietary soybean meal in rainbow trout (Oncorhynchus mykiss) and Atlantic salmon (Salmo salar). Aquaculture, 190, 49-63.

Regost C., Arzel J., Robin J., Rosenlund G., Kaushik S.J., 2003. Total replacement of fish oil by soybean or linseed oil with a return to fish oil in turbot (Psetta maxima): 1. Growth performance, flesh fatty acid profile, and lipid metabolism. Aquaculture, 217, 465-482.

Richard N., Kaushik S., Larroquet L., Panserat S., Corraze G., 2006. Replacing dietary fish oil by vegetable oils has little effect on lipogenesis, lipid transport and tissue lipid uptake in rainbow trout (Oncorhynchus Mykiss). Br. J. Nutr., 96, 299-309.
Robin J.H., Skalli A., 2007. Incorporation of dietary fatty acid in European sea bass (Dicentrarchus labrax) - A methodological approach evidencing losses of highly unsaturated fatty acids. Aquaculture, 263, 227237.

Rodehutscord M., Becker A., Pack M., Pfeffer E., 1997. Response of rainbow trout (Onchorhynchus mykiss) to supplements of individual essential amino acids in a semi purified diet, including an estimate of the maintenance requirement for essential amino acids. J. Nutr., 127, 1166-1175.

Santigosa E., García-Meilán I., Valentin J.M., Pérez-Sánchez J., Médale F., Kaushik S., Gallardo M.A., 2011. Modifications of intestinal nutrient absorption in response to dietary fish meal replacement by plant protein sources in sea bream (Sparus aurata) and rainbow trout (Onchorynchus mykiss). Aquaculture, 317, 146-154.

Seiliez I., Panserat S., Kaushik S., Bergot P., 2001. Cloning, tissue distribution and nutritional regulation of a delta-6-desaturase-like enzyme in rainbow trout. Comp. Biochem. Physiol. B, 130, 83-93.

Sitjá-Bobadilla A., Peña-Llopis S., GómezRequeni P., Médale F., Kaushik S., PérezSánchez J., 2005. Effect of fish meal replacement by plant protein sources on non-specific defence mechanisms and oxidative stress in gilthead sea bream (Sparus aurata). Aquaculture, 249, 387-400.

Stone D.A.J., 2003. Dietary carbohydrate utilization by fish. Rev. Fish. Sci., 11, 337369.

Tacchi L., Secombes C.J., Bickerdike R., Adler M.A., Venegas C., Takle H., Martin S.A.M., 2012. Transcriptomic and physiological responses to fishmeal substitution with plant proteins in formulated feed in farmed Atlantic salmon (Salmo salar). BMC Genomics, $13,1-21$.

Tocher D.R., 2010. Fatty acid requirements in ontogeny of marine and freshwater fish. Aquaculture Res., 41, 717-732.

Tocher D.R., Bell J.G., MacGlaughlin P., McGhee F., Dick J.R., 2001. Hepatocyte fatty acid desaturation and polyunsaturated fatty acid composition of liver in salmonids: effects of dietary vegetable oil. Comp. Biochem. Physiol. B, 130, 257-270.

Torstensen B. E., Bell J.G., Rosenlund G., Henderson R.J., Graff I.E., Tocher D.R., Lie Ø., Sargent J.R., 2005. Tailoring of atlantic salmon (Salmo salar L.) flesh lipid composition and sensory quality by replacing fish oil with a vegetable oil blend. J. Agric. Food Chem., 53, 10166-10178.

Torstensen B. E., Espe M., Stubhaug I., Lie O., 2011. Dietary plant proteins and vegetable oil blends increase adiposity and plasma lipids in Atlantic salmon (Salmo salar L.). Br. J. Nutr., 106, 633-647.

Turchini G.M., Francis D.S., De Silva S.S., 2007. A whole body, in vivo, fatty acid balance method to quantify PUFA metabolism (desaturation, elongation and beta-oxidation). Lipids, 42, 1065-1071.

Turchini G. M., Ng W.K., Tocher D. R., 2010. Fish Oil Replacement and Alternative Lipid Sources in Aquaculture Feeds, Boca Raton, FL: Taylor \& Francis, CRC Press, $513 p$. 
Van den Ingh T.S.G.A.M., Olli J.J., Krogdahl A., 1996. Alcohol-soluble components in soybeans cause morphological changes in the distal intestine of Atlantic salmon (Salmo salar L.) J. Fish Diseases, 19, 47-53.
Van der Werf H.M.G., Petit J., 2002. Evaluation of the environmental impact of agriculture at the farm level: a comparison and analysis of 12 indicator-based methods. Agricult. Ecosys. Environ., 93, 131-145.
Vilhelmsson O.T., Martin S.A.M., Médale F., Kaushik S.J., Houlihan D.F., 2004. Dietary plant-protein substitution affects hepatic metabolism in rainbow trout (Oncorhynchus mykiss). Br. J. Nutr., 92, 71-80.

\title{
Résumé
}

L'aquaculture mondiale se développe (+ $8 \%$ par an) pour répondre à une demande croissante des consommateurs que les captures de pêche ne peuvent plus couvrir. Les besoins en aliments piscicoles et donc en matières premières s'accroissent, alors que les volumes de farines et huiles de poisson, ingrédients traditionnels des aliments aquacoles, ne peuvent augmenter. Selon les espèces, 80 à $95 \%$ de la farine de poisson peut être substituée par un mélange de sources protéiques végétales apportant les acides aminés indispensables en quantité suffisante pour couvrir les besoins des poissons. Au-delà de ce taux de remplacement, on observe une baisse de la consommation d'aliment, de l'efficience alimentaire et de la croissance, bien que les aliments contiennent les nutriments nécessaires aux poissons. Quant à l'huile de poisson, elle peut être remplacée jusqu'à 80 ou $100 \%$ par des huiles végétales sans effet délétère sur la croissance et la santé des poissons, à condition que le régime apporte en quantité suffisante les acides gras essentiels à la couverture des besoins, qui diffèrent selon l'espèce : contrairement aux poissons marins, les salmonidés disposent en effet d'une relative capacité de synthèse d'acides gras longs polyinsaturés omega 3 à partir de l'acide linoléique. La conséquence majeure est une baisse de la teneur de ces acides gras dans la chair. Les recherches doivent se poursuivre pour affranchir encore davantage l'aquaculture des produits de la pêche, en choisissant des matières premières alternatives qui garantissent une production piscicole efficace, des produits de haute qualité et des impacts environnementaux limités.

\begin{abstract}
Plant based diets for farmed fish

World aquaculture is growing $(+8 \%$ per year) to meet the increasing demand of fish for human consumption that capture by fisheries can no longer cover. Consequently, the need for aquafeed and feedstuffs is rising while volumes of fishmeal and fish oil, the traditional aquafeed ingredients, remain stable. More and more fishmeal and fish oil are substituted by plant products. Between 80 and $95 \%$ of fish meal can be replaced by a combination of plant protein sources providing the indispensable amino acids in sufficient quantity to meet the fish needs. Beyond this substitution rate, feed intake, feed efficiency and growth rate decrease and metabolic changes are observed despite the diets containing all the required nutrients. Fish oil can be replaced by a mix of vegetable oils without deleterious effect on fish growth and health, provided that the diet supplies essential fatty acids. Fatty acids requirements vary with species according to their capacity to synthesize EPA and DHA. However, in all species, fish oil substitution results in a reduction in the flesh content of these $\omega 3$ fatty acids. Research must continue to further reduce the reliance of aquaculture on fishery resources while ensuring an efficient fish production of high quality products with limited environmental impacts.
\end{abstract}

MÉDALE F., LE BOUCHER R., DUPONT-NIVET M., QUILLET E., AUBIN J., PANSERAT S., 2013. Des aliments à base de végétaux pour les poissons d'élevage. INRA Prod. Anim., 26, 4, 303-316. 